\title{
Systematic review of methods used in meta-analyses where a primary outcome is an adverse or unintended event
}

\author{
Fiona C Warren ${ }^{1 *}$, Keith R Abrams², Su Golder ${ }^{3}$ and Alex J Sutton ${ }^{2}$
}

\begin{abstract}
Background: Adverse consequences of medical interventions are a source of concern, but clinical trials may lack power to detect elevated rates of such events, while observational studies have inherent limitations. Meta-analysis allows the combination of individual studies, which can increase power and provide stronger evidence relating to adverse events. However, meta-analysis of adverse events has associated methodological challenges. The aim of this study was to systematically identify and review the methodology used in meta-analyses where a primary outcome is an adverse or unintended event, following a therapeutic intervention.
\end{abstract}

Methods: Using a collection of reviews identified previously, 166 references including a meta-analysis were selected for review. At least one of the primary outcomes in each review was an adverse or unintended event. The nature of the intervention, source of funding, number of individual meta-analyses performed, number of primary studies included in the review, and use of meta-analytic methods were all recorded. Specific areas of interest relating to the methods used included the choice of outcome metric, methods of dealing with sparse events, heterogeneity, publication bias and use of individual patient data.

Results: The 166 included reviews were published between 1994 and 2006. Interventions included drugs and surgery among other interventions. Many of the references being reviewed included multiple meta-analyses with $44.6 \%$ (74/166) including more than ten. Randomised trials only were included in $42.2 \%$ of meta-analyses (70/166), observational studies only in $33.7 \%$ (56/166) and a mix of observational studies and trials in $15.7 \%(26 / 166)$. Sparse data, in the form of zero events in one or both arms where the outcome was a count of events, was found in 64 reviews of two-arm studies, of which 41 (64.1\%) had zero events in both arms.

Conclusions: Meta-analyses of adverse events data are common and useful in terms of increasing the power to detect an association with an intervention, especially when the events are infrequent. However, with regard to existing meta-analyses, a wide variety of different methods have been employed, often with no evident rationale for using a particular approach. More specifically, the approach to dealing with zero events varies, and guidelines on this issue would be desirable.

\section{Background}

There is increasing concern regarding adverse outcomes of therapeutic interventions, which may be addressed by bringing together evidence from multiple sources [1]. The Cochrane Collaboration, in its remit to undertake systematic reviews, has considered adverse events as an area

\footnotetext{
*Correspondence: fiona.warren@pcmd.ac.uk

${ }^{1}$ Peninsula College of Medicine and Dentistry, St Luke's Campus, University of Exeter, Exeter, EX1 2LU, UK

Full list of author information is available at the end of the article
}

worthy of consideration as a defined clinical area that requires specific methodology [2], but the emphasis was placed on the non-statistical elements, such as choice of outcomes, study types and search strategies. The use of quantitative evidence synthesis methods with adverse events specifically in mind has been considered some time ago [3], but there is little empirical information collated on meta-analytic approaches within adverse event meta-analyses.

A recent review of systematic reviews of adverse events in response to drug interventions included 43 review 
articles published in 2006 [4]. However, the statistical methods could only be reviewed in the 24 of these that included a meta-analysis. This review also considered the search strategies used in the systematic reviews of adverse events, and this field has been better documented since it is the focus of several further studies [5-9].

The aim of this current systematic review is to investigate the meta-analytic methodology used where the primary outcome of the meta-analysis was an adverse or unintended event, with the aims of identifying which methods have been used and the challenges faced by authors. A wide range of therapeutic interventions are considered, including drugs, surgical procedures, devices, vaccinations, dietary interventions, anaesthetics and public health programmes. It is hoped that this review will assist in development and standardisation of methods in future and we discuss the areas of priority for further research to facilitate the development of guidelines to support meta-analysis of adverse and unintended outcomes data.

\section{Methods}

The dataset of meta-analyses for this current survey was identified using a database of systematic reviews collected previously [7]. The aim of this previous study was to develop and evaluate search strategies for the retrieval of systematic reviews, which may or may not include a metaanalysis, where the primary outcome was an adverse event (or unintended but positive event) resulting from a clinical intervention. The databases searched (both electronically and by hand) in the previous study were the Database of Abstracts of Reviews of Effects (DARE) and the Cochrane Database of Systematic Reviews (CDSR). Details of the search strategy have been described [7].

These search strategies yielded a total of 257 systematic reviews (246 from DARE plus 11 Cochrane reviews), published between 1994 and 2006. The initial searches were updated, yielding a further 20 systematic reviews on adverse events [9], producing 277 in total.

From the systematic reviews above, references were selected for inclusion in the current review according to the following criteria:

1. some form of quantitative synthesis (or test for heterogeneity with intention to perform a quantitative synthesis if appropriate) must be performed using more than one observed estimate of effect;

2. the study group of interest must have received some form of clinical intervention with intended or potential therapeutic effect; and

3. the full study report must be available in English.

A quantitative data synthesis may take the form of a pooled estimate, a confidence interval, quoting a $p$-value only, or performing a meta-regression. Studies entailing only qualitative evidence synthesis, although having an essential role to play in the assessment of adverse events, were not included in this review, which is exclusively aimed at statistical synthesis methods. Meta-analyses of unintended or adverse reactions associated with noninterventional activities, for example recreational drug use, were excluded.

Included reviews were evaluated on multiple aspects. These included type of intervention, number of primary studies incorporated, number of individual meta-analyses performed and source of funding (when determining sponsorship, any form of commercial funding was counted as such, even if other sources of funding were also present; similarly, government sponsorship took precedence over academic). The statistical aspects included general meta-analysis methods and how specific challenges were addressed. These included (i) dealing with sparse data (a count of zero events in one arm of study or zero events across the whole study); (ii) statistical heterogeneity; (iii) dissemination biases (primarily publication bias); (iv) variable quality of primary studies; and (v) use of individual patient data (IPD).

\section{Results}

\section{Description of included reviews}

In total, 166 reviews including a meta-analysis fulfilled all criteria and were included in this systematic review [10-175]. Of these, 14 were Cochrane reviews, the others were published in a wide variety of medical journals or were reviews published by health agencies. Table 1 shows a breakdown of number of included reviews by publication year and type.

Table 1 Number of included reviews by year of publication

\begin{tabular}{lcccc}
\hline $\begin{array}{l}\text { Year of } \\
\text { publication }\end{array}$ & $\begin{array}{c}\text { No. included } \\
\text { reviews (\%) }\end{array}$ & $\begin{array}{c}\text { Published } \\
\text { in journal }\end{array}$ & $\begin{array}{c}\text { Cochrane } \\
\text { review }\end{array}$ & $\begin{array}{c}\text { Other publication } \\
\text { type }\end{array}$ \\
\hline 1994 & $4(2.4)$ & 4 & 0 & 0 \\
1995 & $8(4.8)$ & 8 & 0 & 0 \\
1996 & $9(5.4)$ & 9 & 0 & 0 \\
1997 & $15(9.0)$ & 15 & 0 & 0 \\
1998 & $16(9.6)$ & 16 & 0 & 0 \\
1999 & $19(11.4)$ & 18 & 1 & 0 \\
2000 & $11(6.6)$ & 11 & 0 & 0 \\
2001 & $22(13.3)$ & 22 & 0 & 0 \\
2002 & $21(12.7)$ & 17 & 2 & 2 \\
2003 & $22(13.3)$ & 20 & 2 & 0 \\
2004 & $13(7.8)$ & 10 & 3 & 0 \\
2005 & $4(2.4)$ & 0 & 4 & 0 \\
2006 & $2(1.2)$ & 0 & 2 & 0 \\
\hline 10406 & & & \\
\hline
\end{tabular}

${ }^{1}$ Out of 166 included reviews. 
The interventions being evaluated for adverse events were similarly diverse; by far the largest category was drug interventions $(69.9 \%, 116 / 166)$. The next largest category was surgical interventions $(8.4 \%, 14 / 166)$. Other types of intervention, such as forms of anaesthesia, devices, and diagnostic procedures, each accounted for fewer than $5 \%$ of the included reviews. Multiple interventions (often multiple therapies for cancer being assessed simultaneously) were considered by $5.4 \%$ (9/166) of included reviews.

With regard to sponsorship, the largest number of included reviews were academically sponsored (45.8\%; $76 / 166)$. Commercial sponsorship accounted for $16.3 \%$ (27/166), while $30.1 \%(50 / 166)$ were sponsored by some form of government body. Other sponsorship sources provided funding for $7.2 \%(12 / 166)$, while funding source was not stated for one included review.

Of the 166 included reviews, all except one included some overall combined estimate. The one included review that did not report a combined estimate included a metaregression for dose-response with no overall pooled estimate of effect size.

The number of meta-analyses performed in each included review was also very variable. In many cases a large number of meta-analyses were performed, with $44.6 \%(74 / 166)$ of studies having more than 10 metaanalyses. By comparison, 19.3\% (32/166) of studies had 6-10 meta-analyses, $29.5 \%(49 / 166)$ had $2-5$ metaanalyses, $6.0 \%(10 / 166)$ had only one meta-analysis while $0.60 \%(1 / 166)$ had none (meta-regression only).

The number of primary cohorts (contributing a data observation to the meta-analysis) is shown in Table 2. This

Table 2 Maximum and minimum numbers of contributing estimates for meta-analyses in the same included review

\begin{tabular}{lcc}
\hline $\begin{array}{l}\text { Maximum no. } \\
\text { data observations }\end{array}$ & $\begin{array}{c}\text { Minimum no. } \\
\text { data observations }\end{array}$ & $\begin{array}{c}\text { No. included } \\
\text { reviews (\%) }\end{array}$ \\
\hline $2-5$ & $2-5$ & $17(10.4)$ \\
$6-10$ & $2-5$ & $34(20.7)$ \\
$6-10$ & $6-10$ & $6(3.7)$ \\
$11-20$ & $2-5$ & $50(30.5)$ \\
$11-20$ & $6-10$ & $5(3.0)$ \\
$11-20$ & $11-20$ & $4(2.4)$ \\
$>20$ & $2-5$ & $29(17.7)$ \\
$>20$ & $6-10$ & $12(7.3)$ \\
$>20$ & $11-20$ & $3(1.8)$ \\
$>20$ & $>20$ & $4(2.4)$ \\
\hline
\end{tabular}

${ }^{1} \mathrm{~A}$ single primary study may contribute more than one data observation, hence number of data observations may not be the same as number of primary studies. ${ }^{2}$ Out of 164 included reviews with at least one pooled estimate and number of data observations stated. table indicates that many included reviews performed multiple meta-analyses with varying numbers of data observations derived from primary studies, possibly reflecting multiple outcomes or subgroup analyses.

\section{Statistical methodology aspects}

Table 3 sets out the number of included reviews that cover heterogeneity, quality and dissemination bias, by year of publication, to examine any changes over time.

\section{Outcome measures}

Table 4 shows the proportions of included reviews using different effect measures. This is important because the choice of outcome measure may in itself influence the meta-analysis method and results.

In Table 4 the option 'More than one' was only selected in the eventuality that there was no obvious primary outcome metric, but instead at least two outcome metrics that appeared to receive approximately equal importance in the meta-analyses. Otherwise, the primary outcome measure was recorded even if there were other outcome metrics used in secondary analyses such as sensitivity analyses.

Many of the outcomes being reported in the primary studies were binary, thus lending themselves to analysis by odds ratio or relative risk, as seen in Table 4. A difference scale (for example risk difference), as opposed to a ratio scale, was chosen only infrequently. Only $9.6 \%$ of studies presented more than one outcome measure. This indicated that either more than one clinical outcome was being investigated, requiring a different outcome metric, or that the authors had presented analyses for the same clinical outcome on equal terms for different outcome metrics, possibly intended as a comparison between the two.

\section{Meta-analysis methodology}

Another major area of interest was the methodology used for the meta-analysis itself. Table 5 sets out the meta-analysis method used to combine studies along with numbers and percentages.

As seen in Table 5, fixed and random effect(s) models were used with roughly equal frequency. The term 'standard fixed effect' was used when the authors chose an accepted fixed effect model, such as the Mantel-Haenszel model [176], the inverse variance model or the Peto model [177]. Also, if the authors used any referenced fixed effect model this was recorded as 'standard fixed effect'. In several cases the authors had used a method of combining data that would be considered as a 'fixed effect' model, but appeared to have either used a mean or weighted mean, or a logistic regression method, or had devised their own method for combining data, for example based on sample size of the studies. Such methods were considered 
Table 3 Percentages of included reviews by year including assessment of heterogeneity, quality and dissemination bias

\begin{tabular}{|c|c|c|c|c|}
\hline Year & $\begin{array}{l}\text { Total no. included } \\
\text { reviews }\end{array}$ & $\begin{array}{l}\text { Heterogeneity } \\
\text { (no. (\%)) }\end{array}$ & $\begin{array}{l}\text { Quality } \\
\text { (no. (\%)) }\end{array}$ & $\begin{array}{c}\text { Dissemination bias } \\
(\text { (no. }(\%))\end{array}$ \\
\hline 1994 & 4 & $2(50)$ & $1(25)$ & $1(25)$ \\
\hline 1995 & 8 & $7(88)$ & $1(13)$ & $4(50)$ \\
\hline 1996 & 9 & $8(89)$ & $1(11)$ & $6(67)$ \\
\hline 1997 & 15 & $12(80)$ & $8(53)$ & $5(33)$ \\
\hline 1998 & 16 & $14(88)$ & $3(19)$ & $10(63)$ \\
\hline 1999 & 19 & $18(95)$ & $8(42)$ & $12(63)$ \\
\hline 2000 & 11 & $9(82)$ & $4(36)$ & $4(36)$ \\
\hline 2001 & 22 & $19(86)$ & $8(36)$ & $15(68)$ \\
\hline 2002 & 21 & $16(76)$ & $13(62)$ & $8(38)$ \\
\hline 2003 & 22 & $16(73)$ & $10(45)$ & $15(68)$ \\
\hline 2004 & 13 & $11(85)$ & $7(54)$ & $5(38)$ \\
\hline 2005 & 4 & $4(100)$ & $4(100)$ & $3(75)$ \\
\hline 2006 & 2 & $2(100)$ & $2(100)$ & $1(50)$ \\
\hline
\end{tabular}

non-standard and were recorded as 'other fixed effect'. Interestingly, all the random effects models were referenced standard models (referred to as standard random effects in Table 5, such as the DerSimonian \& Laird model [178]).

A record of 'Multiple analysis methods' was only selected when there was more than one method used on an equal basis. If there was an obvious primary method

\section{Table 4 Measure of effect}

\begin{tabular}{|c|c|c|}
\hline $\begin{array}{l}\text { Measure of } \\
\text { effect }\end{array}$ & $\begin{array}{l}\text { No. included } \\
\text { reviews }\end{array}$ & $\begin{array}{l}\text { Percent included } \\
\text { reviews }^{1}\end{array}$ \\
\hline \multicolumn{3}{|c|}{ Comparative measures (between interventions) } \\
\hline Odds ratio & 55 & 33.1 \\
\hline Relative risk & 51 & 30.7 \\
\hline Risk difference & 8 & 4.8 \\
\hline Mean difference & 6 & 3.6 \\
\hline Standardised mean difference & 7 & 4.2 \\
\hline Percent difference & 2 & 1.2 \\
\hline \multicolumn{3}{|c|}{ Non-comparative measures } \\
\hline Correlation & 2 & 1.2 \\
\hline Probability (or percent) & 13 & 7.8 \\
\hline Mean difference & 2 & 1.2 \\
\hline Percent difference & 3 & 1.8 \\
\hline \multicolumn{3}{|c|}{ Multiple measures } \\
\hline More than one & 16 & 9.6 \\
\hline \multicolumn{3}{|c|}{ Other measures } \\
\hline Other & 1 & 0.6 \\
\hline
\end{tabular}

${ }^{1}$ Out of 166 included reviews. with additional supplementary methods the primary method was chosen.

The one meta-analysis reference referred to as 'Other' used a novel approach developed by the authors of 'summary ranking' involving assigning a score to the rank order of toxicity in individual primary studies, and then combining the scores to provide an overall rank order for toxicity. One study included a meta-regression as the only quantitative analysis, whilst another study performed a test for heterogeneity but did not produce any pooled estimates. In only three cases was there insufficient detail regarding the methodology to allow the type of analysis to be determined. In five of the reviewed studies the meta-analysis method was not stated.

Table 5 Meta-analysis methods

\begin{tabular}{lcc}
\hline $\begin{array}{l}\text { Meta-analysis } \\
\text { method }\end{array}$ & $\begin{array}{c}\text { No. included } \\
\text { reviews }\end{array}$ & $\begin{array}{c}\text { Percent included } \\
\text { reviews }\end{array}$ \\
\hline Standard fixed effect $^{2}$ & 54 & 32.5 \\
Other fixed effect $^{2}$ & 9 & 5.4 \\
Standard random effects $^{2}$ & 50 & 30.1 \\
Marginal analysis & 3 & 1.8 \\
Bayesian methods & 6 & 3.6 \\
Multiple analysis methods & 33 & 19.9 \\
Other & 1 & 0.6 \\
Not stated & 5 & 3.0 \\
Meta-regression only & 1 & 0.6 \\
Heterogeneity test only & 1 & 0.6 \\
Unclear & 3 & 1.8 \\
\hline
\end{tabular}

${ }^{1}$ Out of 166 included reviews.

${ }^{2}$ See text for definition. 
A Bayesian approach was used by six included reviews, but in some cases the Bayesian model used in the meta-analysis was not fully described. Semi-Bayesian methods, incorporating a Bayesian use of a prior distribution on the rate of the adverse event alongside standard frequentist methods, were also used in one included review. This meta-analysis also experimented with the use of different prior distributions for the parameters. However, none of these studies presented graphical representations of the probability densities for the parameters.

Not taking into account the specific method of the metaanalysis, 74/166 (44.6\%) used a fixed effect model. This included one review that stated that a random effects model was used, but in the absence of heterogeneity the presented results were fixed effect. (The novel method using rank summaries was also a fixed effect approach.) Three included reviews where the methodology was not described in sufficient detail to be classed as a standard or other fixed effect model, were, however, able to be classed as fixed effect in their approach.

A random effects model was used by 53/166 (31.9\%) included reviews, including four of the reviews that used Bayesian methods. Hence, it is apparent that fixed and random effect(s) models were used with roughly equal frequency.

Both fixed and random effect(s) models were used in 28/166 (16.9\%) included reviews, including one that used Bayesian methods. In the other cases it was not applicable (5/166; 3.0\%), or not stated $(5 / 166 ; 3.0 \%)$. It was unclear whether fixed or random effect(s) had been used in one included review only.

The reasons why the authors chose a particular model were recorded in 69/166 (41.6\%) included reviews. Reasons based upon heterogeneity (or between-study variation) were the most commonly cited (46/69; 66.7\%). Increased conservatism (of a random effects model) was also frequently mentioned; 7/69 (10.1\%) reviews alluded to this.

Other reasons cited in support for a particular metaanalysis method included differences in primary study types, and so that larger studies would contribute more to the meta-analysis. Arriving at similar results from both fixed and random effect(s) models was also used to justify the chosen approach. Only one included review offered multiple explanations, while nine offered an explanation not mentioned above.

\section{Type of primary study and approaches to inclusion}

The types of primary study encountered by included reviews are set out in Table 6 . The most frequent study type was some form of trial, the sole study type for $46.4 \%(77 / 166)$ of included reviews. Trials were clearly defined as being randomised and/or controlled in some included reviews. The 26 reviews $(26 / 166,15.7 \%)$ that
Table 6 Primary study types incorporated within included reviews

\begin{tabular}{lcc}
\hline Study types & No. included reviews & \% included reviews ${ }^{1}$ \\
\hline Randomised trials & 70 & 42.2 \\
Other trials $^{2}$ & 7 & 4.2 \\
Observational studies & 56 & 33.7 \\
Mixed (trials and & & \\
observational studies) & 26 & 15.7 \\
Not stated & 7 & 4.2 \\
\hline
\end{tabular}

1 Out of 166 included reviews.

${ }^{2}$ May include randomised trials but not specifically stated as such.

included both trials and observational studies demonstrated a wide variety of approaches taken to this situation, often reflecting the number of each different type of study. Some included reviews made no attempt to differentiate by study design. In some included reviews there was only one trial, all other studies were observational, and in one of these reviews, the trial was excluded, although its inclusion did not alter the results. In another instance with only one trial, it was excluded from all meta-analyses, only the observational studies (of different designs) being included. In one included review the sole trial was excluded due to no events being observed in one group of the trial; similarly, in another review with only one trial, this study was excluded due to the small number of outcome events.

The most common approach to mixed study types was to perform a sensitivity analysis by analysing all primary studies together and then dividing the studies by some element of study design. For example, one included review combined all studies together and then casecontrol studies were analysed separately, and cohort studies were combined with trials. Some variation on this theme was followed by several other included reviews. Another approach was to avoid combination of estimates across study designs altogether, by combining results from studies with similar designs.

\section{Graphical representations of data}

Graphical representations of data were used in the majority of included reviews. Forest plots were the only graph used in $53.0 \%(88 / 166)$ of reviews, while meta-regression plots were the only plot in $1.8 \%(3 / 166)$. Both forest plots and meta-regression plots appeared in $1.8 \%(3 / 166)$ of included reviews. Other plots were used in $18.1 \%(30 / 166)$ of included reviews, usually a plot of the individual studies but lacking a pooled estimate. Only $25.3 \%$ (42/166) of included reviews produced no graphical representations of their results.

\section{Publication Bias}

Publication bias was considered in $89 / 166$ (53.6\%) of included reviews. This issue may not have been specifi- 
cally described in terms of publication bias. For example, some included reviews performed searches for unpublished primary studies, indicating that publication bias was within the awareness of the authors when performing a meta-analysis even if it was not taken any further than searching for such primary studies.

Publication bias was discussed but not formally evaluated in 44/166 (26.5\%) included reviews. A quantitative analysis was performed by 31/166 (18.7\%) included reviews. A sensitivity analysis by publication status was the preferred method of investigating publication bias for one review.

Of 31 included reviews with some form of quantitative analysis, $12(38.7 \%)$ used a test with a $p$-value. The other $19 / 31$ (61.3\%) used an alternative method not resulting in a $p$-value. The most commonly used tests were Egger's test [179] and Begg's test [180]. Kendall's tau test was mentioned by three included reviews.

The trim and fill method [181] was used to adjust for publication or selection bias in two included reviews. These were the only reviews that attempted to adjust for these types of bias. Graphical methods (funnel plots) were used to investigate for publication bias (or selection bias) in $29 / 166$ reviews (17.5\%).

The vast majority of included reviews used only published primary studies (129/166; 77.7\%). Published primary studies with unpublished data (obtained through contact with the authors), were used in 20/166 (12.0\%) included reviews. Both published and unpublished primary studies were used in 14/166 (8.4\%) reviews. In the other reviews the study source(s) was either unclear or not stated. In several reviews where published primary studies only were included, it was made clear that unpublished data had been sought.

\section{Heterogeneity}

Heterogeneity was considered in some manner by $138 / 166$ included reviews (83.1\%), whether by a quantitative or qualitative assessment, or by a subgroup analysis or metaregression. Meta-regression was included in nine reviews that had no other assessment of heterogeneity, whilst one review discussed issues regarding combination of primary studies with different criteria, but did not do a formal qualitative or quantitative analysis of heterogeneity. Of the remaining 128 included reviews, a quantitative assessment was performed in 124 (124/166; 74.7\%). A qualitative assessment of heterogeneity (for example, inspection of forest plots or noting heterogeneous results) was made in 10/166 (6.0\%) included reviews. Six included reviews incorporated both quantitative and qualitative aspects of heterogeneity assessment (6/166; 3.6\%).

Considering quantitative analysis methods, 121/166 (72.9\%) included reviews employed some form of statistical test for heterogeneity, although with variation in the chosen critical $p$-value for significance. The chosen significance value was 0.05 for 28 reviews $(23.1 \%$ of the 121 studies that performed a test), while $23 / 121$ chose a more liberal $p$-value of 0.1 (19.0\%). Only one included review chose 0.2 as the cut-off $p$-value. In many reviews the actual $p$-value was quoted without reference to a particular threshold (51/121 reviews (42.1\%) did this). In the other reviews no $p$-value or significance level was stated.

An estimate for heterogeneity was presented by $16 / 121$ included reviews with a quantitative analysis (13.2\%). The most frequently-used estimate measure was the $I^{2}$ statistic [182,183], which was used in 13 reviews. Alternative estimate measures included the between-studies variance. One review used another estimate measure, the $\mathrm{R}(\mathrm{I})$ statistic [184]. Only one included review used multiple estimate measures; the estimates used included $I^{2}$ and the Q statistic [185].

Two ways to investigate the causes of heterogeneity are subgroup analysis and meta-regression. Subgroup analysis was performed in $27 / 128$ (21.1\%) reviews that included an analysis of heterogeneity, and in two reviews that did not formally assess heterogeneity. Meta-regression was used in 27 included reviews in total $(27 / 166 ; 16.3 \%)$. In nine of these reviews, no formal assessment of heterogeneity had been performed. The covariates used in the metaregression analyses were often very specific to the nature of the intervention or outcome being considered. A qualitative investigation of sources of heterogeneity was carried out in $17 / 138$ reviews that considered heterogeneity in some way $(12.3 \%)$.

\section{Individual patient data}

Very little use was made of IPD in the reviewed metaanalyses. Only two included reviews of the total 166 (1.2\%) included IPD. Of these two, all primary studies included had IPD available (so there was no requirement to combine IPD and summary data). Both reviews used a one-stage method for the meta-analysis. In one review the meta-analysis was stratified by trial and other factors including centre within study for multicentre studies and age divisions. In the other review it was not stated whether the meta-analysis was stratified or not.

\section{Sparse data}

The issue of sparse data, whereby statistical methods were required to allow the inclusion of primary studies where the outcome was a count of zero, or a percent of zero, occurred in 65/166 included reviews (39.2\%), one of which was a meta-analysis of single-arm studies only. Specific statistical methods may be required to allow incorporation of such a primary study into an overall pooled estimate or for calculation of confidence intervals. For 62 of the 65 reviews in which sparse data occurred, the outcome was on a comparative scale (an odds ratio, relative 
risk, or risk difference); this methodological area is the focus of this review. The primary issues are (i) outcome measures used by meta-analyses with zero events; (ii) use of continuity corrections; (iii) methods for inclusion of primary studies with zero events that do not involve continuity corrections; and (iv) incorporation of primary studies with zero events in both arms.

Of the 64 included reviews that considered the issue of sparse data in two-arm studies, 41 (64.1\%) had datasets involving double-zero (zero events in both arms) primary studies. In the remaining 23 reviews, only single-zero (zero events in only one arm of a two-arm study) primary studies were present, or it was either unclear or not directly stated whether any double-zero studies were included within the dataset.

Of these 64 reviews, 30 (46.9\%) presented their outcome as an odds ratio, $24(37.5 \%)$ as a relative risk, and two as a risk difference. In six included reviews, there was more than one outcome with roughly equal importance in the meta-analyses. In two reviews, the outcome, where sparse data were incorporated, was an incidence rate.

Continuity corrections were used to circumvent problems with zero counts (in one or both arms of a study) that result in difficulties with estimating ratio-based outcome measures such as the odds ratio. Continuity corrections are also required to calculate the variance (and hence confidence intervals) for a risk difference. However, it was very difficult to determine an accurate picture of how continuity corrections were used.

Some included reviews clearly stated that continuity corrections had been used (15/64, 23.4\%). In 17/64 (26.6\%) included reviews, continuity corrections were not used. In 32 cases it was not clearly stated whether continuity corrections had been used or not.

The most popular primary continuity correction was 0.5 , used in 14 of the 15 included reviews that stated their continuity correction. Only one meta-analysis reference used an alternative continuity correction with 0.25 being the chosen value. Only one review performed a sensitivity analysis across different continuity corrections, using 0.5 , 0.1 and 0.01 , and reported that the continuity correction did not alter the results. Three included reviews provided a reason for their choice of continuity correction, and the only reason cited was to minimise bias.

Several methods for incorporating single- and doublezero studies into a meta-analysis that do not involve continuity corrections were encountered in the included reviews. The most frequently used was the Peto method, employed by 12 studies. The use of a difference metric rather than a ratio as the outcome measure was used to circumvent problems with zeroes in seven reviews, although calculation of confidence intervals with such methods would be problematic. Seven included reviews resorted to the use of marginal analysis. Bayesian methods were used to tackle sparsity of events in only two included reviews.

Double-zero studies were included in analyses in 17 of the 41 reviews where double-zero primary studies were clearly present within the dataset. In two further reviews, double-zero studies were included in a sensitivity analysis. Double-zero studies were clearly excluded from analyses in 18 reviews where they were present in the set of primary studies. Such an exclusion was either a deliberate decision by the authors, shown by excluding the primary study in forest plots of the meta-analysis, or was done by default, the primary study being shown on a forest plot, but being given a weighting of zero. The four remaining included reviews were unclear as to whether or not these double-zero primary studies were included.

Of the 19 included reviews where double-zero primary studies were included in some way, seven made explicit use of continuity corrections. In other included reviews it was not clearly stated whether continuity corrections had been used. Other options, such as using a marginal analysis, were employed in some reviews, whilst in other reviews the methodologies used were unclear.

\section{Discussion}

This paper has reviewed an extensive sample of published meta-analyses where the primary outcome was an adverse or unintended event. Reviews published in languages other than English were excluded, hence there is a risk that methodologies used in reviews published in other languages may differ from those discussed here. There was considerable variation in the methodology employed across the sample, including designs of the primary studies incorporated in the meta-analyses, use of fixed or random effect(s) measures, how to deal with zero events in study arms, and how to assess study quality and publication bias. In many cases, the statistical aspects were not clearly reported, with insufficient detail to discern the methods used. Often, little justification was given for the approaches to meta-analysis used. This is perhaps, in part, due to the lack of specific guidelines available for meta-analysis of sparse/adverse events. Not only would such guidelines improve the standard of reporting of adverse event meta-analyses, they could also circumvent disagreements in the literature due to the use of alternative methods producing different conclusions, as was the case for the recent high-profile concerns of elevated cardiovascular risk in those taking rosiglitazone [186-190].

Based on this review, one of the major areas of confusion appears to be with regard to the use of continuity corrections for dealing with sparse data for comparative outcomes. Indeed the term continuity correction is possibly misleading, as these are in effect nothing more than arbitrary factors added to a cell count of zero. Where 
a study has zero events in both groups, we believe it contains no information regarding the magnitude of the odds ratio or relative risk, but adding a continuity correction to both sides (incorrectly) keeps it in the analysis for methods which require it. Although not required for the risk difference scale, and such a study does contain information, a correction factor is required for the estimation of associated variance which causes further confusion. This latter point also raises the unanswered question of whether the presence of double-zero studies should influence the outcome metric. Bayesian methods present an alternative way to deal with datasets including sparse data, and Bayesian analyses are now easily implemented using appropriate software. However, Bayesian methods were used infrequently within the included reviews; with the development of guidelines to support Bayesian analyses, it may be that such methods would become more popular.

Many reviews in this sample included observational studies, in some cases this was the only type of primary study included, whilst in other reviews both observational studies and trials were included. Observational studies may offer advantages over trials, such as a longer period of follow-up. Inclusion of observational studies also increases the number of studies and individuals within a meta-analysis where both trials and observational studies are available, thus increasing power. However, this advantage may be counterbalanced by concerns regarding bias in observational studies. The reviews included here showed a variety of approaches to mixed study design; this is an area where guidelines would assist in combining all available data whilst addressing issues of different study design.

As mentioned in the introduction, a previous systematic review of reviews and meta-analyses of primary studies of adverse effects of a drug intervention has been conducted [4], including a total of 43 references, all published in 2006. Of these, $15 \%$ assessed quality of primary studies, compared to $42.2 \%$ of references in our review, and only 24 performed a meta-analysis. As seen in our review, there was some poor reporting of the methods used for pooling data, but $83 \%$ did report the method used for pooling data and exploring heterogeneity. With regard to funding source, $23 \%$ (of the 43 reviews) had pharmaceutical funding, compared to the $16.3 \%$ of references in our review that had commercial funding. Hence, there is potentially some suggestion of systematic differences between reviews concerning only drugs and those including other interventions, and between reviews that contain a meta-analysis and those that do not (although such observations could be confounded by the wider time range we considered).

\section{Development of guidelines}

Within the field of meta-analysis for adverse events, the concept of definitive guidelines is possibly too prescrip- tive; the diverse nature of medical interventions, the potential adverse outcomes and the ways they may be measured, and the formats in which data may be available preclude the use of standardised methods. However, general guidelines for approaching specific methodological issues (applying to other outcomes beyond adverse events) may be more feasible and useful. We hope this review sets the context in which future research and guidelines into the conduct of adverse event meta-analyses can be placed.

There is perhaps a need for more research before informed guidelines could be drafted. Many of the unique issues relating to adverse event meta-analyses are due to the typically sparse event data available for such analyses. Such sparse data presents unique challenges, as highlighted by this review. As well as specific challenges, such as dealing with zero events in arms of studies, there are also potential concerns relating to the use of broadly accepted meta-analysis methods in a sparse data context due to the potentially very low power such methods may have. For example, simulation has shown that tests for heterogeneity have very low power in sparse data situations [191,192]. Similar issues are likely to exist for the use of meta-regression, tests for publication bias [193] and other methodologies. Rather than trying to use cuttingedge advanced meta-analysis methodology, in a sparse data context, it may often be wiser to restrict focus to simpler methods (e.g. fixed effect models) and be realistic about the potentially limited conclusions that can be drawn from the data. Since the primary aim of many adverse effect meta-analyses is to establish the existence of an elevated risk of an event due to a particular intervention, use of simple methods is, perhaps, consistent with this aim. Information on the performance of different meta-analytic estimators for sparse data and the use and avoidance of correction factors has been considered at length elsewhere [191,192] and this is one domain in which knowledge on which methods to use and which to avoid is available.

Hierarchical models to address issues related to combination of different study types have been developed [194], and more recent developments on the use of methods to adjust studies in meta-analysis to account for bias appear to be promising $[195,196]$. However, further exploration into the use of such methods in an adverse events context is warranted.

Development of Bayesian methods is clearly an area where further research would be both timely and beneficial, especially in the light of many of the difficulties surrounding meta-analysis of adverse events data, which Bayesian methods may be able to address, such as inclusion of primary studies with sparse events without the need for continuity corrections using Markov Chain Monte Carlo (MCMC) methods [197-200]. However, difficulties exist in ensuring that all prior distributions are 
plausibly vague, when not based on external information - a challenge given how little data is sometimes available [201,202].

Specifically to adverse events, an area where further research would be valuable is the consideration of drug class effects, allowing information on multiple drugs of the same class to be combined while acknowledging the potential differences in effects across drugs. This would be an area where hierarchical (and potentially Bayesian) models would be particularly useful [203]. Another clinical aspect related to adverse events issues is that there may be several indications for a certain intervention; patients with different conditions may be at varying risk of adverse events, despite receiving the same intervention. Whilst it is desirable to combine all available data to increase power, any meta-analysis should be able to adjust for the differences in indication for the intervention; as this scenario is similar to combination of data regarding individual drugs of the same class, hierarchical modelling may be a means to achieve this.

\section{Conclusion}

Conducting meta-analyses where the outcome is an unintended or adverse event presents a range of potential difficulties, and requires careful consideration of the statistical issues, as well as an awareness of the clinical context. This review has demonstrated that a diversity of approaches have been employed when conducting such meta-analyses. Hence, standardised guidelines may be beneficial in this area, even if, due to the range of clinical situations and availability and format of data, they are necessarily of a general nature. This is especially true since a meta-analysis may present the only feasible method to estimate potential risks, due to the often infrequent occurrence of adverse events within an individual trial or observational study.

\section{Competing interests}

The authors declare that they have no competing interests.

\section{Authors' contributions}

FCW selected and reviewed the included references, with guidance from KRA and AJS. SG developed the online search strategies and performed all literature searches (online and by hand). FCW drafted the paper, which was revised by all co-authors. All authors read and approved the final version of the manuscript for publication.

\section{Acknowledgements}

FCW performed this study whilst being supported by a studentship from the Department of Health Sciences, University of Leicester. KRA is partially supported by a National Institute for Health Research (NIHR) Senior Investigator Award (NI-SI-0508-10061). There were no sources of external funding for this study. The authors would like to thank the reviewers for their useful and supportive comments.

\section{Author details}

${ }^{1}$ Peninsula College of Medicine and Dentistry, St Luke's Campus, University of Exeter, Exeter, EX1 2LU, UK. ${ }^{2}$ Department of Health Sciences, Adrian Building, University of Leicester, University Road, Leicester, LE1 7RH, UK. ${ }^{3}$ Centre for Reviews and Dissemination (CRD), University of York, York, YO10 5DD, UK.
Received: 14 June 2011 Accepted: 16 April 2012

Published: 3 May 2012

\section{References}

1. Loke YK, Price D, Herxheimer A, Cochrane Adverse Effects Methods Group: Systematic reviews of adverse effects: framework for a structured approach . BMC Medical Research Methodology 2007, 7:32.

2. Loke YK, Price D, Herxheimer A: Adverse effects. In Cochrane Handbook for Systematic Reviews of Interventions. Edited by Higgins JPT, Green S. Chichester, UK: John Wiley and Sons; 2008:433-449.

3. Sutton A, Cooper N, Lambert P, Jones D, Abrams K, Sweeting M: Meta-analysis of rare and adverse event data. Expert Review of Pharmacoeconomics and Outcomes Research 2002, 2(4):367-379.

4. Cornelius VR, Perrio MJ, Shakir SAW, Smith LA: Systematic reviews of adverse effects of drug interventions: a survey of their conduct and reporting quality. Pharmacoepidemiology and Drug Safety 2009, 18(12):1223-1231.

5. Derry S, Loke YK, Aronson JK: Incomplete evidence: the inadequacy of databases in tracing published adverse drug reactions in clinical trials. BMC Medical Research Methodology 2001, 1:7.

6. Golder S, McIntosh HM, Duffy S, Glanville J: Developing efficient search strategies to identify reports of adverse effects in MEDLINE and EMBASE. Health Information and Libraries Journal 2006, 23(1):3-12.

7. Golder S, McIntosh HM, Loke Y: Identifying systematic reviews of the adverse effects of health care interventions. BMC Medical Research Methodology 2006, 6:22.

8. Golder S, Loke Y, McIntosh HM: Room for improvement? A survey of the methods used in systematic reviews of adverse effects. $B M C$ Medical Research Methodology 2006, 6:3.

9. Golder S, Loke Y, McIntosh HM: Poor reporting and inadequate searches were apparent in systematic reviews of adverse effects. Journal of Clinical Epidemiology 2008, 61(5):440-448.

10. Alfirevic Z, Sundberg K, Brigham S: Amniocentesis and chorionic villus sampling for prenatal diagnosis. Cochrane Database of Systematic Reviews 2003 doi:10.1002/14651858.CD003252. Issue 3(Art. No.: CD003252)

11. Allen DB, Mullen M, Mullen B: A meta-analysis of the effect of oral and inhaled corticosteroids on growth. Journal of Allergy and Clinical Immunology 1994, 93(6):967-976.

12. Allison DB, Mentore JL, Heo M, Chandler LP, Cappelleri JC, Infante MC, Weiden PJ: Antipsychotic-induced weight gain: a comprehensive research synthesis. American Journal of Psychiatry 1999, 156(11):1686-1696.

13. Anderson JW, Kendall CWC, Jenkins DJA: Importance of weight management in Type 2 diabetes: review with meta-analysis of clinical studies. Journal of the American College of Nutrition 2003, 22(5):331-333.

14. Anderson-Hanley C, Sherman ML, Riggs R, Agocha VB, Compas BE: Neuropsychological effects of treatments for adults with cancer: a meta-analysis and review of the literature. Journal of the International Neuropsychological Society 2003, 9(7):967-982.

15. Ashcroft DM, Chapman SR, Clark WK, Millson DS: Upper gastroduodenal ulceration in arthritis patients treated with celecoxib. Annals of Pharmacotherapy 2001, 35(7-8):829-834.

16. Ashraf E, Cooper S, Kellstein D, Jayawardena S: Safety profile of nonprescription ibuprofen in the elderly osteoarthritis patient: a meta-analysis. Inflammopharmacology 2001, 9(1-2):35-41.

17. Banks E: Hormone replacement therapy and the sensitivity and specificity of breast cancer screening: a review. Journal of Medical Screening 2001, 8(1):29-35.

18. Barbui C, Saraceno B: Low-dose neuroleptic therapy and extrapyramidal side effects in schizophrenia: an effect size analysis. European Psychiatry 1996, 11(8):412-415.

19. Barone JE, Tucker JB, Rassias D, Corvo PR: Routine perioperative pulmonary artery catheterization has no effect on rate of complications in vascular surgery: a meta-analysis. American Surgeon 2001, 67(7):674-679.

20. Ben-David S, Einarson T, Ben-David Y, Nulman I, Pastuszak A, Koren G: The safety of nitrofurantoin during the first trimester of pregnancy: meta-analysis. Fundamental and Clinical Pharmacology 1995, 9(5):503-507. 
21. Bender BG, Berning S, Dudden R, Milgrom H, Tran ZV: Sedation and performance impairment of diphenhydramine and second-generation antihistamines: a meta-analysis. Journal of Allergy and Clinical Immunology 2003, 111(4):770-776.

22. Berglundh $T$, Persson $L$, Klinge $B$ : A systematic review of the incidence of biological and technical complications in implant dentistry reported in prospective longitudinal studies of at least 5 years. Journal of Clinical Periodontology 2002, 29(Supplement 3):197-212.

23. Bernal-Delgado E, Latour-Perez J, Pradas-Arnal F, Gomez-Lopez LI: The association between vasectomy and prostate cancer: a systematic review of the literature. Fertility and Sterility 1998, 70(2):191-200.

24. Brown JS, Sawaya G, Thom DH, Grady D: Hysterectomy and urinary incontinence: a systematic review. Lancet 2000, 356(9229):535-539.

25. Brown S, Small R, Faber B, Krastev A, Davis P: Early postnatal discharge from hospital for healthy mothers and term infants. Cochrane Database of Systematic Reviews 2002 doi:10.1002/14651858.CD002958. Issue 3(Art. No.: CD002958).

26. Brumback BA, Holmes LB, Ryan LM: Adverse effects of chorionic villus sampling: a meta-analysis. Statistics in Medicine 1999,

18(16):2163-2175

27. Cannegieter SC, Rosendaal FR, Briet E: Thromboembolic and bleeding complications in patients with mechanical heart valve prostheses. Circulation 1994, 89(2):635-641.

28. Caraballo PJ, Gabriel SE, Castro MR, Atkinson EJ, Melton LJ: Changes in bone density after exposure to oral anticoagulants: a meta-analysis. Osteoporosis International 1999, 9(5):441-448.

29. Cardwell ME, Siviter G, Smith AF: Non-steroidal anti-inflammatory drugs and perioperative bleeding in paediatric tonsillectomy. Cochrane Database of Systematic Reviews 2005 doi:10.1002/14651858.CD003591.pub2. Issue 2(Art. No.: CD003591).

30. Caro-Paton T, Carvajal A, Martin de Diego I, Martin-Arias LH, Alvarez Requejo A, Rodriguez Pinilla E: Is metronidazole teratogenic: a meta-analysis. British Journal of Clinical Pharmacology 1997 44(2):179-182.

31. Chan WS, Ray J, Wai EK, Ginsburg S, Hannah ME, Corey PN, Ginsberg JS: Risk of stroke in women exposed to low-dose oral contraceptives: a critical evaluation of the evidence. Archives of Internal Medicine 2004, 164(7):741-747.

32. Chang $\mathrm{CH}$, Chen KY, Lai MY, Chan KA: Meta-analysis: ribavirin-induced haemolytic anaemia in patients with chronic hepatitis $C$. Alimentary Pharmacology and Therapeutics 2002, 16(9):1623-1632.

33. Chapron C, Fauconnier A, Goffinet F, Breart G, Dubuisson JB: Laparoscopic surgery is not inherently dangerous for patients presenting with benign gynaecologic pathology: results of a meta-analysis. Human Reproduction 2002, 17(5):1334-1342.

34. Choi PT, Galinski SE, Takeuchi L, Lucas S, Tamayo C, Jadad AR: PDPH is a common complication of neuraxial blockade in parturients: $a$ meta-analysis of obstetrical studies. Canadian Journal of Anaesthesia 2003, 50(5):460-469.

35. Col NF, Hirota LK, Orr RK, Erban JK, Wong JB, Lau J: Hormone replacement therapy after breast cancer: a systematic review and quantitative assessment of risk. Journal of Clinical Oncology 2001, 19(8):2357-2363.

36. Collaborative Group on Hormonal Factors in Breast Cancer: Breast cancer and hormonal contraceptives: collaborative reanalysis of individual data on 53297 women with breast cancer and 100239 women without breast cancer from $\mathbf{5 4}$ epidemiological studies. Lancet 1996, 347(9017):1713-1727.

37. Correll CU, Leucht S, Kane JM: Lower risk for tardive dyskinesia associated with second-generation antipsychotics: a systematic review of 1-year studies. American Journal of Psychiatry 2004 161(3):414-425

38. Coughlin SS, Giustozzi A, Smith SJ, Lee NC: A meta-analysis of estrogen replacement therapy and risk of epithelial ovarian cancer. Journal of Clinical Epidemiology 2000, 53(4):367-375.

39. Cutler C, Giri S, Jeyapalan S, Paniagua D, Viswanathan A, Antin JH: Acute and chronic graft-versus-host disease after allogeneic peripheral-blood stem-cell and bone marrow transplantation: a meta-analysis. Journal of Clinical Oncology 2001, 19(16):3685-3691.

40. Derry S, Loke YK: Risk of gastrointestinal haemorrhage with long term use of aspirin: meta-analysis. BMJ 2000, 321(7270):1183-1187.
41. Dezfulian C, Lavelle J, Nallamothu BK, Kaufman SR, Saint S: Rates of infection for single-lumen versus multilumen central venous catheters: a meta-analysis. Critical Care Medicine 2003, 31(9):2385-2390.

42. DiMatteo MR, Morton SC, Lepper HS, Damush TM, Carney MF, Pearson M, Kahn KL: Cesarean childbirth and psychosocial outcomes: a meta-analysis. Health Psychology 1996, 15(4):303-314

43. Dolovich LR, Addis A, Vaillancourt RJ, Power BJ, Koren G, Einarson TR: Benzodiazepine use in pregnancy and major malformations of oral cleft: meta-analysis of cohort and case-control studies. BMJ 1998 317(7162):839-843.

44. Dong EW, Connelly JE, Borden SP, Yorzyk W, Passov DG, Kupelnick B, Luo $\mathrm{DH}$, Ross SD: A systematic review and meta-analysis of the incidence of cancer in randomized, controlled trials of verapamil. Pharmacotherapy 1997, 17(6):1210-1219.

45. Doren M, Nilsson JA, Johnell O: Effects of specific post-menopausal hormone therapies on bone mineral density in post-menopausal women: a meta-analysis. Human Reproduction 2003, 18(8):1737-1746.

46. Douketis JD, Ginsberg JS, Holbrook A, Crowther M, Duku EK, Burrows RF: A reevaluation of the risk for venous thromboembolism with the use of oral contraceptives and hormone replacement therapy. Archives of Internal Medicine 1997, 157(14):1522-1530.

47. Doyle LW, Davis PG: Postnatal corticosteroids in preterm infants: systematic review of effects on mortality and motor function. Journal of Paediatrics and Child Health 2000, 36(2):101-107.

48. Duffy $G$, Neal KR: Differences in post-operative infection rates between patients receiving autologous and allogeneic blood transfusion: a meta-analysis of published randomized and nonrandomized studies. Transfusion Medicine 1996, 6(4):325-328.

49. Egger M, Davey Smith G, Stettler C, Diem P: Risk of adverse effects of intensified treatment in insulin-dependent diabetes mellitus: a meta-analysis. Diabetic Medicine 1997, 14(11):919-928.

50. Eikelboom JW, Mehta SR, Pogue J, Yusuf S: Safety outcomes in meta-analyses of phase 2 vs phase 3 randomized trials: intracranial hemorrhage in trials of bolus thrombolytic therapy. JAMA 2001, 285(4):444-450.

51. Etminan $M$, Samii A, Takkouche B, Rochon PA: Increased risk of somnolence with the new dopamine agonists in patients with Parkinson's disease: a meta-analysis of randomised controlled trials. Drug Safety 2001, 24(11):863-868.

52. Etminan M, Gill S, Samii A: Comparison of the risk of adverse events with pramipexole and ropinirole in patients with Parkinson's disease: a meta-analysis. Drug Safety 2003, 26(6):439-444.

53. Etminan M, Gill S, Samii A: Effect of non-steroidal anti-inflammatory drugs on risk of Alzheimer's disease: systematic review and meta-analysis of observational studies. BMJ 2003, 327(7407):128-131

54. Fernandez E, La Vecchia, C, Balducci A, Chatenoud L, Franceschi S, Negri $\mathrm{E}$ : Oral contraceptives and colorectal cancer risk: a meta-analysis. British Journal of Cancer 2001, 84(5):722-727.

55. Furberg CD, Psaty BM, Meyer JV: Nifedipine: dose-related increase in mortality in patients with coronary heart disease. Circulation 1995, 92(5):1326-1331.

56. Gabriel Sánchez R, Carmona L, Roque M, Sánchez Gomez LM, Bonfill X: Hormone replacement therapy for preventing cardiovascular disease in post-menopausal women. Cochrane Database of Systematic Reviews 2005 doi:10.1002/14651858.CD002229.pub2. Issue 2(Art. No. CD002229).

57. Garcia Rodriguez LA: Nonsteroidal antiinflammatory drugs, ulcers and risk: a collaborative meta-analysis. Seminars in Arthritis and Rheumatism 1997, 26(6 Supplement 1):16-20.

58. Garcia Rodriguez LA, Hernandez-Diaz S, de Abajo FJ: Association between aspirin and upper gastrointestinal complications: systematic review of epidemiologic studies. British Journal of Clinical Pharmacology 2001, 52(5):563-571.

59. Garg PP, Kerlikowske K, Subak L, Grady D: Hormone replacement therapy and the risk of epithelial ovarian carcinoma: a meta-analysis. Obstetrics and Gynecology 1998, 92(3):472-479.

60. Gillum LA, Mamidipudi SK, Claiborne Johnston S: Ischemic stroke risk with oral contraceptives: a meta-analysis. JAMA 2000, 284(1):72-78. 
61. Gordon PV, Young ML, Marshall DD: Focal small bowel perforation: an adverse effect of early postnatal dexamethasone therapy in extremely low birth weight infants. Journal of Perinatology 2001, 21(3):156-160.

62. Grady D, Gebretsadik T, Kerlikowske K, Ernster V, Petitti D: Hormone replacement therapy and endometrial cancer risk: a meta-analysis. Obstetrics and Gynecology 1995, 85(2):304-313.

63. Graham GD: Tissue plasminogen activator for acute ischemic stroke in clinical practice: a meta-analysis of safety data. Stroke 2003, 34(12):2847-2850.

64. Greenland S, Satterfield MH, Lanes SF: A meta-analysis to assess the incidence of adverse effects associated with the transdermal nicotine patch. Drug Safety 1998, 18(4):297-308.

65. Grodstein F, Newcomb PA, Stampfer MJ: Postmenopausal hormone therapy and the risk of colorectal cancer: a review and meta-analysis. American Journal of Medicine 1999, 106(5):574-582.

66. Grossman E, Messerli FH: Effect of calcium antagonists on plasma norepinephrine levels, heart rate, and blood pressure. American Journal of Cardiology 1997, 80(11):1453-1458.

67. Guise JM, Berlin M, McDonagh M, Osterweil P, Chan B, Helfand M: Safety of vaginal birth after cesarean: a systematic review. Obstetrics and Gynecology 2004, 103(3):420-429.

68. Gupta P, Sachdev HP: Safety of oral use of nimesulide in children: systematic review of randomized controlled trials. Indian Pediatrics 2003, 40(6):518-531.

69. Hart RG, Benavente $O$, Pearce $L A$ : Increased risk of intracranial hemorrhage when aspirin is combined with warfarin: a meta-analysis and hypothesis. Cerebrovascular Diseases 1999, 9(4):215-217.

70. Hauth JC, Goldenberg RL, Parker CR, Cutter GR, Cliver SP: Low-dose aspirin: lack of association with an increase in abruptio placentae or perinatal mortality. Obstetrics and Gynecology 1995, 85(6):1055-1058.

71. He J, Whelton PK, Vu B, Klag MJ: Aspirin and risk of hemorrhagic stroke: a meta-analysis of randomized controlled trials. JAMA 1998, 280(22):1930-1935.

72. Hébert-Croteau N: A meta-analysis of hormone replacement therapy and colon cancer in women. Cancer Epidemiology, Biomarkers \& Prevention 1998, 7(8):653-659.

73. Heisel $O$, Heisel R, Balshaw R, Keown P: New onset diabetes mellitus in patients receiving calcineurin inhibitors: a systematic review and meta-analysis. American Journal of Transplantation 2004, 4(4):583-595.

74. Henk JM: Controlled trials of synchronous chemotherapy with radiotherapy in head and neck cancer: overview of radiation morbidity. Clinical Oncology 1997, 9(5):308-312.

75. Hennessy S, Berlin JA, Kinman JL, Margolis DJ, Marcus SM, Strom BL: Risk of venous thromboembolism from oral contraceptives containing gestodene and desogestrel versus levonorgestrel: a meta-analysis and formal sensitivity analysis. Contraception 2001, 64(2):125-133.

76. Henry D, McGettigan P: Epidemiology overview of gastrointestinal and renal toxicity of NSAIDs. International Journal of Clinical Practice 2003, 135(Supplement):43-49.

77. Hoes AW, Grobbee DE, Peet TM, Lubsen J: Do non-potassium sparing diuretics increase the risk of sudden cardiac death in hypertensive patients: recent evidence. Drugs 1994, 47(5):711-733.

78. Huang JQ, Sridhar S, Hunt RH: Gastrointestinal safety profile of nabumetone: a meta-analysis. American Journal of Medicine 1999, 107(6A):55S-61S.

79. Humphrey LL, Takano LMA, Chan BKS: Postmenopausal hormone replacement therapy and cardiovascular disease [Systematic evidence review no. 10]. Rockville, MD: Agency for Healthcare Research and Quality; 2002.

80. Hwang BF, Jaakkola JJ: Water chlorination and birth defects: a systematic review and meta-analysis. Archives of Environmental Health 2003, 58(2):83-91

81. Impicciatore $P$, Choonara I, Clarkson A, Provasi D, Pandolfini C, Bonati M: Incidence of adverse drug reactions in paediatric in/out-patients: a systematic review and meta-analysis of prospective studies. British Journal of Clinical Pharmacology 2001, 52(1):77-83.

82. Ismail Al, Bandekar RR: Fluoride supplements and fluorosis: a meta-analysis. Community Dentistry and Oral Epidemiology 1999, 27(1):48-56.
83. Ivanov R, Allen J, Calvin JE: The incidence of major morbidity in critically ill patients managed with pulmonary artery catheters: a meta-analysis. Critical Care Medicine 2000, 28(3):615-619.

84. Janowsky EC, Kupper LL, Hulka BS: Meta-analysis of the relation between silicone breast implants and the risk of connective tissue diseases. New England Journal of Medicine 2000, 342(11):781-790.

85. Johnson AG, Nguyen TV, Day RO: Do nonsteroidal anti-inflammatory drugs affect blood pressure: a meta-analysis. Annals of Internal Medicine 1994, 121(4):289-300.

86. Johnston SC, Colford JJM, Gress DR: Oral contraceptives and the risk of subarachnoid hemorrhage: a meta-analysis. Neurology 1998, 51(2):411-418

87. Jolles BM, Bogoch ER: Posterior versus lateral surgical approach for total hip arthroplasty in adults with osteoarthritis. Cochrane Database of Systematic Reviews 2006 doi:10.1002/14651858.CD003828.pub3. Issue 3(Art. No.: CD003828).

88. Jones $\mathrm{G}$, Riley M, Couper D, Dwyer T: Water fluoridation, bone mass and fracture: a quantitative overview of the literature. Australian and New Zealand Journal of Public Health 1999, 23(1):34-40.

89. Jonker-Pool: Sexual functioning after treatment for testicular cancer: review and meta-analysis of 36 empirical studies between 1975-2000. Archives of Sexual Behavior 2001, 30(1):55-74.

90. Kellstein DE, Waksman JA, Furey SA, Binstok G, Cooper SA: The safety profile of nonprescription ibuprofen in multiple-dose use: a meta-analysis. Journal of Clinical Pharmacology 1999, 39(5):520-532.

91. Kemmeren JM, Algra A, Grobbee DE: Third generation oral contraceptives and risk of venous thrombosis: meta-analysis. $B M J$ 2001, 323(7305):131-134.

92. Khader YS, Rice J, John L, Abueita O: Oral contraceptives use and the risk of myocardial infarction: a meta-analysis. Contraception 2003, 68(1):11-17.

93. Ko DT, Hebert PR, Coffey CS, Sedrakyan A, Curtis JP, Krumholz HM: Beta-blocker therapy and symptoms of depression, fatigue, and sexual dysfunction. JAMA 2002, 288(3):351-357.

94. Ko DT, Hebert PR, Coffey CS, Curtis JP, Foody JM, Sedrakyan A, Krumholz $\mathrm{HM}$ : Adverse effects of beta-blocker therapy for patients with heart failure: a quality overview of randomized trials. Archives of Internal Medicine 2004, 164(13):1389-1394.

95. Kongnyuy EJ, Norman RJ, Flight IHK, Rees MCP: Oestrogen and progestogen hormone replacement therapy for peri-menopausal and post-menopausal women: weight and body fat distribution. Cochrane Database of Systematic Reviews 1999 doi:10.1002/14651858.CD001018. Issue 3(Art. No.: CD001018).

96. Kozer E, Nikfar S, Costei A, Boskovic R, Nulman I, Koren G: Aspirin consumption during the first trimester of pregnancy and congenital anomalies: a meta-analysis. American Journal of Obstetrics and Gynecology 2002, 187(6):1623-1630.

97. Lazarou J, Pomeranz BH, Corey PN: Incidence of adverse drug reactions in hospitalized patients: a meta-analysis of prospective studies. JAMA 1998, 279(15):1200-1205.

98. LeBlanc ES, Janowsky J, Chan BK, Nelson HD: Hormone replacement therapy and cognition: systematic review and meta-analysis. JAMA 2001, 285(11):1489-1499.

99. Lee TM, Yip JT, Jones-Gotman M: Memory deficits after resection from left or right anterior temporal lobe in humans: a meta-analytic review. Epilepsia 2002, 43(3):283-291.

100. Lee A, Cooper MC, Craig JC, Knight JF, Keneally JP: Effects of nonsteroidal anti-inflammatory drugs on postoperative renal function in adults with normal renal function. Cochrane Database of Systematic Reviews 2004 doi:10.1002/14651858.CD002765. Issue 2(Art No.: CD002765)

101. Leipzig RM, Cumming RG, Tinetti ME: Drugs and falls in older people: a systematic review and meta-analysis. I. Psychotropic drugs. Journal of the American Geriatrics Society 1999, 47(1):30-39.

102. Leipzig RM, Cumming RG, Tinetti ME: Drugs and falls in older people: a systematic review and meta-analysis. II. Cardiac and analgesic drugs. Journal of the American Geriatrics Society 1999, 47(1):40-50.

103. Lethaby A, Suckling J, Barlow D, Farquhar CM, Jepson RG, Roberts H: Hormone replacement therapy in postmenopausal women: endometrial hyperplasia and irregular bleeding. Cochrane Database 
of Systematic Reviews 2004 doi:10.1002/14651858.CD000402. Issue 3(Art. No.: CD000402).

104. Lipworth BJ: Systemic adverse effects of inhaled corticosteroid therapy: a systematic review and meta-analysis. Archives of Internal Medicine 1999, 159(9):941-955.

105. Liu EH, Sia AT: Rates of Caesarean section and instrumental vaginal delivery in nulliparous women after low concentration epidural infusions or opioid analgesia: systematic review. BMJ 2004, 328(7453):1410-1412.

106. Loke YK, Derry S, Pritchard-Copley A: Appetite suppressants and valvular heart disease: a systematic review. BMC Clinical Pharmacology 2002, 2:6.

107. MacLennan SC, MacLennan AH, Ryan P: Colorectal cancer and oestrogen replacement therapy: a meta-analysis of epidemiological studies. Medical Journal of Australia 1995, 162(9):491-493.

108. Marcolongo R, Frediani B, Biasi G, Minari C, Barreca C: A meta-analysis of the tolerability of amtolmetin guacil, a novel, effective nonsteroidal anti-inflammatory drug, compared with established agents. Clinical Drug Investigation 1999, 17(2):89-96.

109. Mardirosoff C, Dumont L, Boulvain M, Tramer MR: Fetal bradycardia due to intrathecal opioids for labour analgesia: a systematic review. BJOG: an International Journal of Obstetrics and Gynaecology 2002, 109(3):274-281.

110. McAlister FA, Clark HD, Wells PS, Laupacis A: Perioperative allogeneic blood transfusion does not cause adverse sequelae in patients with cancer: a meta-analysis of unconfounded studies. British Journal of Surgery 1998, 85(2):171-178.

111. Mehta SR, Eikelboom JW, Yusuf S: Risk of intracranial haemorrhage with bolus versus infusion thrombolytic therapy: a meta-analysis. Lancet 2000, 356(9228):449-454.

112. Miller J, Chan BK, Nelson H: Hormone replacement therapy and risk of venous thromboembolism. [Systematic evidence review no. 11]. Rockville, MD: Agency for Healthcare Research and Quality; 2002

113. Moiniche S, Romsing J, Dahl JB, Tramer MR: Nonsteroidal antiinflammatory drugs and the risk of operative site bleeding after tonsillectomy: a quantitative systematic review. Anesthesia and Analgesia 2003, 96(1):68-77.

114. Mol BW, Ankum WM, Bossuyt PM, Van der Veen, F: Contraception and the risk of ectopic pregnancy: a meta-analysis. Contraception 1995, 52(6):337-341

115. Muldoon MF, Manuck SB, Mendelsohn AB, Kaplan JR, Belle SH: Cholesterol reduction and non-illness mortality: meta-analysis of randomised clinical trials. BMJ 2000, 322(7277):11-15.

116. Nalysnyk L, Fahrbach K, Reynolds MW, Zhao SZ, Ross S: Adverse events in coronary artery bypass graft (CABG) trials: a systematic review and analysis. Heart 2003, 89(7):767-772.

117. Nanda K, Bastian LA, Hasselblad V, Simel DL: Hormone replacement therapy and the risk of colorectal cancer: a meta-analysis. Obstetrics and Gynecology 1999, 93(5 Part 2 Supplement S):880-888.

118. Nazareth I, Lewin J, King M: Sexual dysfunction after treatment for testicular cancer: a systematic review. Journal of Psychosomatic Research 2001, 51(6):735-743.

119. O'Connell D, Robertson J, Henry D, Gillespie W: A systematic review of the skeletal effects of estrogen therapy in postmenopausal women. II. An assessment of treatment effects. Climacteric 1998, 1(2):112-123.

120. Ofman JJ, MacLean CH, Straus WL, Morton SC, Berger ML, Roth EA, Shekelle $P$ : A metaanalysis of severe upper gastrointestinal complications of nonsteroidal antiinflammatory drugs. Journal of Rheumatology 2002, 29(4):804-812.

121. Ofman JJ, Maclean CH, Straus WL, Morton SC, Berger ML, Roth EA, Shekelle PG: Meta-analysis of dyspepsia and nonsteroidal antiinflammatory drugs. Arthritis and Rheumatism 2003, 49(4):508-518.

122. Oger $E$, Scarabin PY: Assessment of the risk for venous thromboembolism among users of hormone replacement therapy. Drugs and Aging 1999, 14(1):55-61.

123. Olsen O: Meta-analysis of the safety of home birth. Birth 1997 24(1):4-13

124. Park-Wyllie L, Mazzotta P, Pastuszak A, Moretti ME, Beique L, Hunnisett L, Friesen MH, Jacobson S, Kasapinovic S, Chang D, Diav-Citrin O, Chitayat
D, Nulman I, Einarson TR, Koren G: Birth defects after maternal exposure to corticosteroids: prospective cohort study and meta-analysis of epidemiological studies. Teratology 2000, 62(6):385-392.

125. Pfahlberg A, Hassan K, Wille L, Lausen B, Gefeller O: Systematic review of case-control studies: oral contraceptives show no effect on melanoma risk. Public Health Reviews 1997, 25(3-4):309-315.

126. Pladevall-Vila M, Delclos GL, Varas C, Guyer H, Brugues-Tarradellas J, Anglada-Arisa A: Controversy of oral contraceptives and risk of rheumatoid arthritis: meta-analysis of conflicting studies and review of conflicting meta-analyses with special emphasis on analysis of heterogeneity. American Journal of Epidemiology 1996 144(1):1-14

127. Raaijmakers $E$, Engelen AM: Is sensorineural hearing loss a possible side effect of nasopharyngeal and parotid irradiation: a systematic review of the literature. Radiotherapy and Oncology 2002, 65(1):1-7.

128. Ray JG, O'Brien TE, Chan WS: Preconception care and the risk of congenital anomalies in the offspring of women with diabetes mellitus: a meta-analysis. QJM: An International Journal of Medicine 2001, 94(8):435-444.

129. Reid FD, Mercer PM, Harrison M, Bates T: Cholecystectomy as a risk factor for colorectal cancer: a meta-analysis. Scandinavian Journal of Gastroenterology 1996, 31(2):160-169.

130. Reynolds F, Sharma SK, Seed PT: Analgesia in labour and fetal acid-base balance: a meta-analysis comparing epidural with systemic opioid analgesia. BJOG: an International Journal of Obstetrics and Gynaecology 2002, 109(12):1344-1353.

131. Robinson JW, Dufour MS, Fung TS: Erectile functioning of men treated for prostate carcinoma. Cancer 1997, 79(3):538-544.

132. Ross SD, Kupelnick B, Kumashiro M, Arellano FM, Mohanty N, Allen IE: Risk of serious adverse events in hypertensive patients receiving isradipine: a meta-analysis. Journal of Human Hypertension 1997, 11(11):743-751.

133. Ross SD, Akhras KS, Zhang S, Rozinsky M, Nalysnyk L: Discontinuation of antihypertensive drugs due to adverse events: a systematic review and meta-analysis. Pharmacotherapy 2001, 21 (8):940-953.

134. Rothwell PM, Slattery J, Warlow CP: A systematic comparison of the risks of stroke and death due to carotid endarterectomy for symptomatic and asymptomatic stenosis. Stroke 1996, 27(2):266-269.

135. Rothwell PM, Slattery J, Warlow CP: A systematic review of the risks of stroke and death due to endarterectomy for symptomatic carotid stenosis. Stroke 1996, 27(2):260-265.

136. Ruesch S, Walder B, Tramer MR: Complications of central venous catheters. Internal jugular versus subclavian access: a systematic review. Critical Care Medicine 2002, 30(2):454-460.

137. Rutschmann OT, McCrory DC, Matchar DB: Immunization and MS: a summary of published evidence and recommendations. Neurology 2002, 59(12):1837-1843.

138. Sachdev M, Miller WC, Ryan T, Jolis JG: Effect of fenfluraminederivative diet pills on cardiac valves: a meta-analysis of observational studies. American Heart Journal 2002, 144(6):1065-1073.

139. Safdar N, Said A, Gangnon RE, Maki DG: Risk of hemolytic uremic syndrome after antibiotic treatment of Escherichia coli 0157:H7 enteritis: a meta-analysis. JAMA 2002, 288(8):996-1000.

140. Sagsveen M, Farmer JE, Prentice A, Breeze A: Gonadotrophin-releasing hormone analogues for endometriosis: bone mineral density. Cochrane Database of Systematic Reviews 2003 doi:10.1002/14651858.CD001297. Issue 4(Art. No.: CD001297).

141. Sakai H, Hayashi K, Origasa H, Kusunoki T: An application of meta-analysis techniques in the evaluation of adverse experiences with antihypertensive agents. Pharmacoepidemiology and Drug Safety 1999, 8(3):169-177.

142. Salpeter SR, Ormiston TM, Salpeter EE, Wood-Baker R: Cardioselective beta-blockers for reversible airway disease. Cochrane Database of Systematic Reviews 2002 doi:10.1002/14651858.CD002992. Issue 4(Art. No.: CD002992).

143. Salpeter SR, Greyber E, Pasternak GA, Salpeter EE: Risk of fatal and nonfatal lactic acidosis with metformin use in type 2 diabetes mellitus. Archives of Internal Medicine 2003, 163(21):2594-2602. 
144. Salpeter SR, Walsh JM, Greyber E, Ormiston TM, Salpeter EE: Mortality associated with hormone replacement therapy in younger and older women: a meta-analysis. Journal of General Internal Medicine 2004, 19(7):791-804.

145. Salpeter SR, Ormiston TM, Salpeter EE: Cardioselective beta-blockers for chronic obstructive pulmonary disease. Cochrane Database of Systematic Reviews 2005 doi:10.1002/14651858.CD003566.pub2. Issue 4(Art. No.: CD003566).

146. Salpeter SR, Greyber E, Pasternak GA, Salpeter EE: Risk of fatal and nonfatal lactic acidosis with metformin use in type 2 diabetes mellitus. Cochrane Database of Systematic Reviews 2006 doi:10.1002/14651858.CD002967.pub2. Issue 1(Art. No.: CD002967)

147. Schaumberg DA, Dana MR, Christen WG, Glynn RJ: A systematic overview of the incidence of posterior capsule opacification. Ophthalmology 1998, 105(7):1213-1221.

148. Schoenfeld P: Gastrointestinal safety profile of meloxicam: a meta-analysis and systematic review of randomized controlled trials. American Journal of Medicine 1999, 107(6A):48S-54S.

149. Serebruany VL, Malinin Al, Eisert RM, Sane DC: Risk of bleeding complications with antiplatelet agents: meta-analysis of 338,191 patients enrolled in $\mathbf{5 0}$ randomized controlled trials. American Journal of Hematology 2004, 75(1):40-47.

150. Seto A, Einarson T, Koren G: Pregnancy outcome following first trimester exposure to antihistamines: meta-analysis. American Journal of Perinatology 1997, 14(3):119-124.

151. Smith JS, Green J, Berrington de Gonzalez A, Appleby P, Peto J, Plummer $M$, Franceschi S, Beral V: Cervical cancer and use of hormonal contraceptives: a systematic review. Lancet 2003 361(9364):1159-1167.

152. Sneyd JR, Carr A, Byrom WD, Bilski AJ: A meta-analysis of nausea and vomiting following maintenance of anaesthesia with propofol or inhalational agents. European Journal of Anaesthesiology 1998, 15(4):433-445

153. Stason WB, Schmid CH, Niedzwiecki D, Whiting GW, Caubet JF, Luo D, Ross SD, Chalmers TC: Safety of nifedipine in patients with hypertension: a meta-analysis. Hypertension 1997, 30(1 Part 1):7-14.

154. Stason WB, Schmid CH, Niedzwiecki D, Whiting GW, Caubet JF, Cory D, Luo D, Ross SD, Chalmers TC: Safety of nifedipine in angina pectoris: a meta-analysis. Hypertension 1999, 33(1):24-31.

155. Torgerson DJ, Bell-Syer SEM: Hormone replacement therapy and prevention of nonvertebral fractures: a meta-analysis of randomized trials. JAMA 2001, 285(22):2891-2897.

156. Torgerson DJ, Bell-Syer SEM: Hormone replacement therapy and prevention of vertebral fractures: a meta-analysis of randomised trials. BMC Musculoskeletal Disorders 2001, 2:7

157. Torvaldsen S, Roberts CL, Bell JC, Raynes-Greenow CH: Discontinuation of epidural analgesia late in labour for reducing the adverse delivery outcomes associated with epidural analgesia. Cochrane Database of Systematic Reviews 2004 doi:10.1002/14651858.CD004457.pub2. Issue 4(Art. No.: CD004457).

158. Tramer MR, Moore RA, Reynolds DJ, McQuay HJ: Quantitative estimation of rare adverse events which follow a biological progression: a new model applied to chronic NSAID use. Pain 2000, 85(1-2):169-182.

159. Trindade E, Menon D, Topfer LA, Coloma C: Adverse effects associated with selective serotonin reuptake inhibitors and tricyclic antidepressants: a meta-analysis. Canadian Medical Association Journal 1998, 159(10):1245-1252.

160. Uzzan B, Campos J, Cucherat M, Nony P, Boissel JP, Perret GY: Effects on bone mass of long term treatment with thyroid hormones: a meta-analysis. Journal of Clinical Endocrinology and Metabolism 1996, 81(12):4278-4289.

161. Vamvakas EC: Perioperative blood transfusion and cancer recurrence: meta-analysis for explanation. Transfusion 1995 , 35(9):760-768

162. Vamvakas EC: Meta-analysis of randomized controlled trials investigating the risk of postoperative infection in association with white blood cell-containing allogeneic blood transfusion: the effects of the type of transfused red blood cell product and surgical setting. Transfusion Medicine Reviews 2002, 16(4):304-314.
163. Vamvakas EC: WBC-containing allogeneic blood transfusion and mortality: a meta-analysis of randomized controlled trials. Transfusion 2003, 43(7):963-973.

164. Vercauteren SB, Bosmans JL, Elseviers MM, Verpooten GA, De Broe, M E A meta-analysis and morphological review of cyclosporine-induced nephrotoxicity in auto-immune diseases. Kidney International 1998, 54(2):536-545.

165. Verhoeven AC, Boers M: Limited bone loss due to corticosteroids: a systematic review of prospective studies in rheumatoid arthritis and other diseases. Journal of Rheumatology 1997, 24(8):1495-1503.

166. von Dadelszen P, Ornstein MP, Bull SB, Logan AG, Koren G, Magee LA: Fall in mean arterial pressure and fetal growth restriction in pregnancy hypertension: a meta-analysis. Lancet 2000, 355(9198):87-92.

167. Vorperian VR, Havighurst TC, Miller S, January CT: Adverse effects of low dose amiodarone: a meta-analysis. Journal of the American College of Cardiology 1997, 30(3):791-798.

168. Warltier DCE, Marret E, Flahault A, Samama CM, Bonnet F: Effects of postoperative, nonsteroidal, antiinflammatory drugs on bleeding risk after tonsillectomy: meta-analysis of randomized, controlled trials. Anesthesiology 2003, 98(6):1497-1502.

169. Waterman EJ, Magee LA, Lim Kl, Skoll A, Rurak D, von Dadelszen P: Do commonly used oral antihypertensives alter fetal or neonatal heart rate characteristics: a systematic review. Hypertension in Pregnancy 2004, 23(2):155-169.

170. Wehling M: Meta-analysis of flecainide safety in patients with supraventricular arrhythmias. Arzneimittel-Forschung Drug Research 2002, 52(7):507-514

171. Wiffen $P$, Gill M, Edwards J, Moore A: Adverse drug reactions in hospital patients: a systematic review of the prospective and retrospective studies. Bandolier Extra 2002, 101:4.

172. Wilson K, Mottram P: A comparison of side effects of selective serotonin reuptake inhibitors and tricyclic antidepressants in older depressed patients: a meta-analysis. International Journal of Geriatric Psychiatry 2004, 19(8):754-762.

173. Xiong $X$, Buekens $P$, Wollast $E$ : IUD use and the risk of ectopic pregnancy: a meta-analysis of case-control studies. Contraception 1995, 52(1):23-34

174. Yaffe K, Sawaya G, Lieberburg I, Grady D: Estrogen therapy in postmenopausal women: effects on cognitive function and dementia. JAMA 1998, 279(9):688-695.

175. Zaric DDZ, Christiansen CCC, Pace NL, Punjasawadwong Y: Transient neurologic symptoms (TNS) following spinal anaesthesia with lidocaine versus other local anaesthetics. Cochrane Database of Systematic Reviews 2005 doi:10.1002/14651858.CD003006.pub2. Issue 4(Art. No.: CD003006).

176. Mantel N, Haenszel W: Statistical aspects of the analysis of data from retrospective studies of disease. Journal of the National Cancer Institute 1959, 22(4):719-748.

177. Yusuf S, Peto R, Lewis J, Collins R, Sleight P: Beta blockade during and after myocardial infarction: an overview of the randomized trials. Progress in Cardiovascular Diseases 1985, 27(5):353-371.

178. DerSimonian R, Laird N: Meta-analysis in clinical trials. Controlled clinical trials 1986, 7(3):177-188.

179. Egger M, Davey Smith G, Schneider M, Minder C: Bias in meta-analysis detected by a simple, graphical test. BMJ 1997, 315(7109):629-634.

180. Begg CB, Mazumdar M: Operating characteristics of a rank correlation test for publication bias. Biometrics 1994, 50(4):1088-1101

181. Duval S, Tweedie R: Trim and fill: A simple funnel-plot-based method of testing and adjusting for publication bias in meta-analysis. Biometrics 2000, 56(2):455-463.

182. Higgins JPT, Thompson SG: Quantifying heterogeneity in a meta-analysis. Statistics in Medicine 2002, 21(11):1539-1558.

183. Higgins JPT, Thompson SG, Deeks JJ, Altman DG: Measuring inconsistency in meta-analyses. BMJ 2003, 327(7414):557-560

184. Takkouche B, Cadarso-Suárez C, Spiegelman D: Evaluation of old and new tests of heterogeneity in epidemiologic meta-analysis. American Journal of Epidemiology 1999, 150(2):206-215.

185. Berlin JA, Laird NM, Sacks HS, Chalmers TC: A comparison of statistical methods for combining event rates from clinical trials. Statistics in Medicine 1989, 8(2):141-151. 
186. Nissen S, Wolski K: Effect of rosiglitazone on the risk of myocardial infarction and death from cardiovascular causes. New England Journal of Medicine 2007, 356(24):2457-2471.

187. Diamond $G A, B o x L$, Kaul $S$ : Uncertain effects of rosiglitazone on the risk for myocardial infarction and cardiovascular death. Annals of Internal Medicine 2007, 147(8):578-581.

188. Bracken MB: Rosiglitazone and cardiovascular risk. New England Journal of Medicine 2007, 357(9):937-938.

189. Cobitz A, Zambanini A, Sowell M, Heise M, Louridas B, McMorn S, Semigran M, Koch G: A retrospective evaluation of congestive heart failure and myocardial ischemia events in 14237 patients with type $\mathbf{2}$ diabetes mellitus enrolled in $\mathbf{4 2}$ short-term, double-blind, randomized clinical studies with rosiglitazone. Pharmacoepidemiology and Drug Safety 2008, 17(8):769-781.

190. Nissen SE, Wolski K: Rosiglitazone revisited: an updated meta-analysis of risk for myocardial infarction and cardiovascular mortality. Archives of Internal Medicine 2010, 170(14):1191-1201.

191. Sweeting MJ, Sutton AJ, Lambert PC: What to add to nothing? Use and avoidance of continuity corrections in meta-analysis of sparse data. Statistics in Medicine 2004, 23(9):1351-1375.

192. Bradburn MJ, Deeks JJ, Berlin JA, Localio AR: Much ado about nothing: a comparison of the performance of meta-analytical methods with rare events. Statistics in Medicine 2007, 26(1):53-77.

193. Ioannidis JPA, Trikalinos TA: The appropriateness of asymmetry tests for publication bias in meta-analyses: a large survey. Canadian Medical Association Journal 2007, 176(8):1091-1096.

194. Prevost TC, Abrams KR, Jones DR: Hierarchical models in generalized synthesis of evidence: an example based on studies of breast cancer screening. Statistics in Medicine 2000, 19(24):3359-3376.

195. Turner RM, Spiegelhalter DJ, Smith GCS, Thompson SG: Bias modelling in evidence synthesis. Journal of the Royal Statistical Society Series A Statistics in Society 2009, 172(1):21-47.

196. Welton NJ, Ades AE, Carlin JB, Altman DG, Sterne JAC: Models for potentially biased evidence in meta-analysis using empirically based priors. Journal of the Royal Statistical Society Series A - Statistics in Society 2009, 172(1):119-136.

197. Carlin JB: Meta-analysis for $\mathbf{2} \times \mathbf{2}$ tables - a Bayesian approach. Statistics in Medicine 1992, 11(2):141-158.

198. Ashby D, Hutton JL, McGee MA: Simple Bayesian analyses for case-control studies in cancer epidemiology. Statistician 1993, 42(4):385-397.

199. Ashby D, Hutton JL: Bayesian epidemiology. New York, NY, USA; 1996

200. Sutton AJ, Abrams KR: Bayesian methods in meta-analysis and evidence synthesis. Statistical Methods in Medical Research 2001 10(4):277-303.

201. Spiegelhalter D, Abrams K, Myles J: Bayesian approaches to clinical trials and healthcare evaluation. Chichester, UK: John Wiley \& Sons; 2004.

202. Lambert PC, Sutton AJ, Burton PR, Abrams KR, Jones DR: How vague is vague? A simulation study of the impact of the use of vague prior distributions in MCMC using WinBUGS. Statistics in Medicine 2005, 24(15):2401-2428.

203. Warren FC: An exploration of evidence synthesis methods for adverse events. PhD thesis, University of Leicester, Department of Health Sciences 2010.

\section{doi:10.1186/1471-2288-12-64}

Cite this article as: Warren et al.: Systematic review of methods used in meta-analyses where a primary outcome is an adverse or unintended event. BMC Medical Research Methodology 2012 12:64.

\section{Submit your next manuscript to BioMed Central} and take full advantage of:

- Convenient online submission

- Thorough peer review

- No space constraints or color figure charges

- Immediate publication on acceptance

- Inclusion in PubMed, CAS, Scopus and Google Scholar

- Research which is freely available for redistribution

Submit your manuscript at www.biomedcentral.com/submit
C Biomed Central 